2020, Volume 10, International Conference Globalization, Innovation and Development. Trends and Prospects (G.I.D.T.P.), pages: 25-32 | https://doi.org/10.18662/lumproc/gidtp2018/04

\section{Public Hospitals Performance. Theoretical Foundations and Challenges}

\section{Constanța POPESCU ${ }^{1}$, Gulay (Avci) KAKILLIOGLU²}

${ }^{1}$ Faculty of Economic Sciences, "Valahia" University of Targoviste, Romania, tantapop@yahoo.com Corresponding author

2 Doctoral School of Economics and Humanities, Management, "Valahia" University of Targoviste, Romania, gkakillioglu@yahoo.com
Abstract: Public hospitals performance is currently a public management subject of great interest. On the one hand, there is the pressure of the State and of the taxpayer (health insurance payer), which have expectations regarding the capitalisation of health expenditures. On the other hand, there is the pressure put by users, as consumers, who want to have the power to choose in a field they consider essential for their state of health. In these circumstances, the following questions arise: How do public hospitals see performance? Do they consider this performance requirement a threat, in the context of public and private sector competition, or do they see it as a real opportunity to improve the quality of the services provided to users (patients) and ensure an efficient State governance (as the State is the one financing public health services)? Our article aims at answering these questions, which represent major challenges for a national health system.

Keywords: health insurance system; hospital system; hospital performance; healthcare quality.

How to cite: Popescu, C., \& Kakillioglu, G. A. (2020). Public Hospitals Performance. Theoretical Foundations and Challenges. In I. Panagoreț \& G. Gorghiu (vol. ed.), Lumen Proceedings: Vol. 10. International Conference Globalization, Innovation and Development. Trends and Prospects (G.I.D.T.P.) (pp. 25-32). Iasi, Romania: LUMEN Publishing House. https://doi.org/10.18662/lumproc/gidtp2018/04 


\section{Introduction}

The healthcare system contribution to health status is regarded as minor (approximately $20 \%$ according to the most frequently quoted figures [9]), which, a contrario, proves the importance of determinants related to the individuals forming a population, as well as of numerous other factors such as social and physical environment, social-economic level and its distribution, education level or living conditions. Therefore, the definition of the investigated area becomes critical when aiming at measuring the "performance" of a national or regional health system [2]:

- "The health system in its entirety or", as was the case of the WHO Report (2000), which approached the system from a broader perspective, including all decisive factors which contribute to a better state of health (income level and its distribution, education, social support, consumer habits);

- "The healthcare system" (including all actors);

- "The hospital system", which, depending on the country, places the hospital on a certain position within the healthcare system, depending on financing methods.

Our analysis shall only refer to the concept of performance applied to public hospitals: assessment methods, limits and impact. In order to understand the emergence of the performance concept of applied to public hospitals, a dual analysis is required: at national and international level.

The performance of healthcare establishments is a major concern for international organisations, in particular WHO and OECD, organisations which conducted studies aimed at defining comparison and assessment frameworks of national systems with different cultural and historical backgrounds. They are interested in the definition of performance both from a methodological and a regulatory point of view: it must allow each national health system to position itself in comparison to the other systems and find realistic and efficient methods to overcome possible performance gaps[8].

At national level, the first performance models appeared early-on, in Anglo-Saxon countries. In the United Kingdom, Florence Nightingale developed in 1859 the first hospital performance charts [6]. Starting with 1912, the USA understood the importance of performance assessment in the health sector and in particular for health establishments (hospitals); "An assessment system for hospital equipment and activity should be developed, so as to grant acknowledgement to the institutions with the highest standards of professionalism and motive those with lower quality equipment and personnel training to improve the quality of 
their activity. Consequently, patients will receive the best treatment and the population will have the means to identify the best hospitals and professionals" [5].

\section{Basic definition of public hospitals performance}

The actors of the health services market - public authorities, service providers and patients - have different needs and requirements. As such, hospital performance is perceived from various points of view, corresponding to the expectations of each type of actor:

- Hospital managers propose services accessible to all patients, observing care continuity in the context of more and more important regulatory constraints;

- Patients claim the right to receive the best care possible while admitted to a hospital;

- Society (general population) expects hospitals to be involved in the organisation and participate to public health prevention actions, in a coherent and balanced manner, integrated with the healthcare network, organised on three levels: primary (family physicians), secondary (polyclinics) and tertiary (hospitals);

- University hospitals have their own missions related to specialised higher education and research.

Therefore, from the point of view of performance, there are several expectations for a hospital. A hospital cannot be considered efficient if it does not fulfil all the missions entrusted to it [7].

Performance is a complex multi-dimensional concept, a characteristic also found in the definition of the healthcare quality concept [1]. According to $\mathrm{WHO}$ definition, the assessment of healthcare must allow for ,the guarantee that each patient shall receive a mix of diagnosis and therapeutic actions which will provide the best result in terms of health, at the actual development stage of medical science, for the most cost-effective combination for the same result, with the lowest iatrogenic risk and highest satisfaction in terms of procedures, results and human contacts within the healthcare system"[11].

Performance and in particular its progress, must be supported by a performance policy, defining the mission, vision or strategy of the establishment (in our case the hospital)[6]. The performance policy vision can be viewed as a philosophy supporting the measurement of performance [3].

Performance policy and measurement are inseparable and closely related. Therefore, performance policy sets the major guidelines for performance measurement, while, in its turn, performance measurement 
defines the indicators to be analysed for further adjustment of the performance policy's strategy or mission directions [5].

\section{Measurement of medical performance as viewed by WHO}

WHO defines four methods for measuring hospital performance:

1) Hospital inspection or audit, measuring compliance with minimum patient and personnel security standards;

2) Inquires or surveys, focusing mainly on the aspects important for patients and the general public;

3) Third-party certifications: standards, such as ISO or certification programmes;

4) Statistical indicators.

If the first three performance measurement alternatives are "external" assessment methods, since they depend on a certification made by a third party, either clients or control bodies, the last method - statistical indicators - defines performance on the basis of the strategy developed by a specific entity (such as the hospital).

WHO believes that performance assessment models must be part of a regional or national plan, i.e. a general framework for all the hospitals located in the same area. Therefore, WHO favours generic models, suitable for national and international comparisons.

The project "Performance Assessment Tool for Quality Improvement in Hospitals" (PATH) was drawn-upby the WHO Regional Office for Europe, in order to come tohospitals' aidduring data collectionactions, to identify hospital comparison methods and initiate quality improvement dynamics [4].

The PATH model general framework includes six performance dimensions, of which four "fields": clinical effectiveness, production efficiency, staff trainingand responsive governance; and two crossperspectives: safety and patient-focus.

This model takes up the multi-dimensional performance analysis of the "balanced scorecard", by introducing transversal dimensions in the analysis, applied to the domains assembly. Each performance dimension is divided into sub-dimensions in text box 1.

The PATH model ",supplies an integrated system which includes the measurement tool, assessment and actions. Its distinctive character is represented by the fact that it focuses on understanding indicators. There is the mention that indicators cannot be interpreted individually. The PATH project does not provide a list of indicators, but a 
model. Therefore, by approaching all performance dimensions, the team of researchers has established a model" [4].

Text box 1

\section{Performance dimensions (WHO Regional Office for Europe)}

- Clinical effectiveness $\rightarrow$ effectiveness and quality within the integrated model

- Care processes

- Resultsof care processes

- $\rightarrow$ care appropriateness within the integrated model

- Efficiency $\rightarrow$ output within the integrated model

- inputs approached as a system (they have an interdependency relation) with care outputs

- Maximal use of available technology for best possible care

\section{- Staff training}

- Practice environment

- $\quad$ Perspectives and recognition of individual needs

- Health awarenessactivities and safety initiatives

- Behavioural responses and health status

\section{- Responsive governance}

- System/community integration

- Public health orientation

- Safety

- Patient safety

- Staff safety

- Environment safety

- Patient-focus $\rightarrow$ quality (continuity) within the integrated model

- Client orientation,

- $\quad$ Respect for patients

Source: CHAMPAGNE, F. si al., op.cit., p.28.

\section{Healthcare quality assessment methodological framework promoted by OECD}

Political decision-makers must measure, assess and compare healthcare quality for three main reasons: 1) make healthcare providers more responsible; 2) develop better adjusted performance policies; 3) allow healthcare providers and other involved parties to continuously improve their specialised training. At the same time, in order to achieve "a quality- 
oriented governance", the system's capacity to provide effective, safe and patient oriented care must be analysed.

The OECD Health Care Quality Indicators project (HCQI) was launched in 2001. Its core objective is to develop a suiteof indicators based on which new research directions regarding the quality of health service provision in OECD member countriescanbefound. Finally, these indicators must be scientifically relevant and clinically and strategically important. They must be readily available for collection, i.e. associated data must be available and comparable at international level. These indicators must allow for an assessment of the global performance of healthcare systems in their entirety. Essentially, they should be used as a starting point for understanding of existing differences and identification of gap reduction means, so as to obtain an improvement of healthcare in all OECD member countries.

The main aspects approached by the HCQI project are clinical effectiveness, patient safety and patient experience. A series of recommendations on the measurement of healthcare quality, with direct impact on the improvement of hospital performance were made at the Forum on quality in healthcare, organised in Paris between October 7-8, 2010 [10].

A brief overview of subjects debated at the Forum is useful in the context of our undertaking. Four areas of interest emerged from the Forum's works:

1) Usefulness of the healthcare quality information. A fundamental axis of policies aimed at the improvement of healthcare systems performance is the measurement of care quality. The information necessary to fulfil this purpose should monitor the following aspects: improvement of care coordination (efforts to replace the fragmentation of healthcare systems with an integrated care system); prevention at the centre of the healthcare system (progressive transition from a curative approach to a more anticipatory and preventive approach of disease); patient-oriented care (measurement of patient experience, of their overall satisfaction with the medical acts); systematic use of sanitary technology and clinical assessments (advantages and disadvantages of various treatment methods, such as diagnostic tests, medicines, medical devices); compensation based on performance (performance compensation programmes, involving a series of incentive indicators by rewarding providers for the quality of the healthcare offered); quality-oriented governance (use of care quality data for the optimisation of healthcare systems performance; data comparable at international level should be integrated with national performance reports).

2) Identification of data comparable at international level, relevant for bealthcare quality. An international comparative analysis should not be limited to a comparison of costs and indicators such as, for example, mortality rates 
and life expectancy. It is recommended that these comparative analyses also focus on effectiveness, patient experience and care safety.

3) Measures and ways of obtaining accurate and complete data, in order to inform and make the involved parties more responsible: the Ministry of Health, coordinators of public healthcare actions, medical professionals. The HCQI project has identified five major sources of information useful in the monitoring of healthcare quality: statistics on life expectancy (for example, mortality rate); registers (organised by disease or speciality, such as cancer or transmissible diseases registers); administrative databases (hospital databases connected to payment systems or pharmaceutical databases on prescription plans); electronic medical records; inquiries of the population and patients (for example on the subject of patient experience).

4) Methods and ways of using quality information in order to improve bealthcare. Quality indicators cannot influence the performance of healthcare systems if they are not clearly connected with the national policies and strategies aiming at the improvement of care quality.

\section{Conclusions}

Healthcare could have potential major advantages, but also significant risks, in particular mediocre quality, which could endanger the life and well-being of the population. As stated in the OECD study [11], mediocre healthcare could compromise all the objectives of modern healthcare systems, because it generates great patient dissatisfaction, premature mortality, an increase of health costs and could lead to an aggravation of discrepancies in the health sector.

Therefore, it is essential for each country to encourage the continuous monitoring and assessment of the quality of the main healthcare strategies, focusing mainly on the key aspects of quality: effectiveness, safety and patient.

Taking into account the varying data quality at international level, comparisons of healthcare systems are limited. Often, the insufficiency of health-related data is the consequence of the absence of an adequate communication infrastructure in the health sector. Hence, public authorities in each country should take more interest in creating and developing an infrastructure which facilitates and ensures a governance focused on the quality of healthcare services, integrated in a well-balanced and coherent national system, which is sensitive to the needs of the population, and at the same time cost-effective. 


\section{References}

[1]. Anhoury P, Viens G. (eds.). Gérer la qualité et les risques àl'hôpital. Paris: ESF Editeurs; 1994: 22.

[2]. Baubeau D, Pereira C. Mesure de la performance dans le domaine de la santé. Présentation au 10-ième Colloque de Comptabilité Nationale, Paris, 22 janvier 2004: 2

[3]. Boland T, Fowler A. A Systems Perspective of Performance Management in Public Sector Organisations. Int J Public Sector Manag. 2000; 13: 417-446.

[4]. Champagne F, Contandriopoulos A-P, Picot-Touché J, Béland F, Nguyen H. Un cadre d'évaluation de la performance des systèmes de service de santé: le modèle EGIPSS (Évaluation globale et intégrée de la performance des systèmes de santé). Université de Montréal. 2005; 28.

[5]. Jacques J. Indicateurs de performance clinique hospitalière. Etudes empiriques basée sur les données médico-administratives belges. Thèse présentée en vue de l'obtention du grade de docteur en sciences de la santé publique. Université de Liège. 2012-2013: 9.

[6]. Kesley T. Améliorer la qualité des soins, in L'observateur de l'OCDE, nr. 229, Royaume Uni, Novembre. 2001; 229: 1.

[7]. Lombrail P, Naiditch D, Baubeau D, Cuneo P. Les éléments de la performance hospitalière. Les conditions d'une comparaison, Etudes etrésultats, DREES 42. 1999: 1-8.

[8]. Marty C, Merlin H. Mesurer la performance des hôpitaux public en France. Fundements méthodologiques, proposition d'un modèle d'evaluation, enjeux, HEC Paris, Observatoire du Management Alternatif, Cahier de recherche. 2007: 15. Available from:

https://creativecommons.org/licenses/by/2.0/fr/

[9]. OCDE. Les systèmes de santé. Paris: OCDE; 1990.

[10]. OECD. Améliorer la performance des soins de santé: comment mesurer leur qualité, Forum sur la qualité des soins, Paris, 2010 octobre.

[11]. World Health Organisation, Regional Office for Europe. Measuring hospitals performance to improve the quality of care in Europe: a need for clarifying the concepts and defining the main dimensions. Report on a WHO Workshop Barcelona, Spain. 10-11 January 2003: 8. 